\title{
Altered or Impaired Immune Response to Hepatitis B Vaccine in WNIN/GR-Ob Rat: An Obese Rat Model with Impaired Glucose Tolerance
}

\author{
Prathibha Bandaru, ${ }^{1}$ Hemalatha Rajkumar, ${ }^{1}$ and Giridharan Nappanveettil ${ }^{2}$ \\ ${ }^{1}$ Department of Microbiology, National Institute of Nutrition, Jamai Osmania, Hyderabad 500 604, India \\ ${ }^{2}$ National Centre for Laboratory Animal Sciences, National Institute of Nutrition, Indian Council of Medical Research, \\ Jamai Osmania, Andhra Pradesh, Hyderabad 500 604, India
}

Correspondence should be addressed to Giridharan Nappanveettil, nappanveettil@yahoo.co.in

Received 14 May 2011; Accepted 19 June 2011

Academic Editors: C. Anderwald and W. B. Chan

Copyright ( $) 2011$ Prathibha Bandaru et al. This is an open access article distributed under the Creative Commons Attribution License, which permits unrestricted use, distribution, and reproduction in any medium, provided the original work is properly cited.

\begin{abstract}
Obesity is shown to increase the incidence and severity of infectious diseases and individuals seem to exhibit poor antibody response to vaccination due to several inherent immune defects. With the increasing prevalence of impaired glucose tolerance (IGT) seen in obese individuals, the present study was aimed to investigate the basal immune response and immune response upon Hepatitis B vaccination (HBV) in an obese rat model WNIN/GR-Ob with impaired glucose tolerance (IGT). Decreased proportions of splenic $\mathrm{CD}^{+} \mathrm{T}$ helper cells and $\mathrm{CD}^{+} \mathrm{T}$ cells were observed in obese animals compared to lean animals. Upon HBV, obese animals showed reduced cell-mediated immunity and humoral immunity in terms of splenic lymphocyte proliferative response to Concanavalin A (Con A) and Hepatitis B surface antigen (HBsAg) and HBsAg-specific IgG response. Innate immunity as assessed in terms of Tumor Necrosis Factor $\alpha$ (TNF $\alpha$ ) and Nitric oxide (NO) production by peritoneal macrophages upon HBV was low and unchanged, respectively, in obese animals. Thus long-term immunological memory is impaired or altered upon HBV.
\end{abstract}

\section{Introduction}

Obesity is often associated with increased risk of degenerative diseases like type 2 diabetes, cardiovascular disease (CVD), and cancer [1]. However, clinically a positive correlation between body weight index and incidence of nosocomial infections was also observed [2]. Increased infections were reported in genetically obese and diet-induced obese rodent models. For example, Zucker obese rats showed an increased susceptibility to Candida albicans infections [3], while $\mathrm{Ob} / \mathrm{Ob}$ mice displayed impaired immune response to Listeria monocytogenes and Candida albicans [4]. In diet-induced obese (DIO) rodent models, a poor response to Porphyromonas gingivalis infection were observed and infection with influenza virus seemed to cause high mortality rate in mice $[5,6]$.

In obese individuals reduction in lymphocyte numbers and reduced responsiveness to mitogen were observed $[7,8]$. Defects in specific immunity such as reduced lymphocyte numbers in spleen, thymus, and peripheral blood have been reported in $\mathrm{Ob} / \mathrm{Ob}$ and $\mathrm{db} / \mathrm{db}$ mice and fa/fa Zucker rats [9]. Diminished responsiveness to mitogen as well as cytotoxic activity was also seen in these animals [9]. Same was true in DIO models where reduced lymphocyte response and altered cytokine secretion were observed [10]. Poor antibody response was reported in obese individuals and overweight children's against vaccination [11-13]. Furthermore, reduced lymphocyte function upon $\mathrm{HBV}$ was observed in WNIN/Ob obese rat [14].

In recent years, increased prevalence of obesity in both the developed and developing countries is accompanied by a parallel rise in the incidence of impaired glucose tolerance (IGT) both in adults and children. In this context, an attempt was made to study the immune response in an obese rat model with IGT. At National Institute of Nutrition, we have a spontaneously mutated obese rat model, namely, WNIN/ GR-Ob, which exhibits the whole gamut of characteristics of metabolic syndrome [15-18]. In general, the fasting blood 
glucose levels of these obese animals are $90-100 \mathrm{mg} / \mathrm{dL}$, whereas oral lavage with glucose at a dose of $250 \mathrm{mg} / 100 \mathrm{~g}$ body weight, the $1 \mathrm{~h}$ and $2 \mathrm{~h}$ blood glucose levels, were beyond $140 \mathrm{mg} / \mathrm{dL}$ suggesting that the animals exhibited impaired glucose tolerance [19]. These animals also develop kidney dysfunction, tumors, and opportunistic infections as they cross one year of age and their life span is short (1.5 years versus 3 years of normal rats) suggesting an altered or impaired immune function. In the present study, basal immune response and immune response to Hepatitis B vaccine (HBV) was studied in WNIN/GR-Ob obese rat with IGT.

\section{Materials and Methods}

\subsection{Studies on Basic Immune Response}

2.1.1. Animals. 90 -day old 8 female rats of lean $(+/+)$ and obese $(-/-)$ phenotypes were obtained from the stock colony of NCLAS and were fed on standard pellet diet. Animals were housed individually in the animal facility with proper temperature $\left(22 \pm 2^{\circ} \mathrm{C}\right)$, humidity (50-55\%), and light control (12 h light and $12 \mathrm{~h}$ darkness) and were provided with ad libitum rat chow and water. The study design had the approval of the Institutional Animal Ethical Committee (IAEC). Blood was collected through retroorbital sinus and the animals were sacrificed to perform the following immune parameters.

2.1.2. Body and Spleen Weights. Body weights of the animals were taken. Animals were euthanized using $\mathrm{CO}_{2}$ inhalation and spleen was removed aseptically and weighed. The spleen weight was then normalized to gram body weight.

2.1.3. Splenic Lymphocyte Proliferation Assay. Lymphocyte proliferation assay was performed as previously described [20]. Briefly, splenocytes were dissociated by using a stainless steel screen and adjusted to $1 \times 10^{9}$ cells/L RPMI 1640 medium supplemented with $40,000 \mu \mathrm{g} / \mathrm{L}$ gentamycin and $5 \%$ FBS (Sigma-Aldrich). $200 \mu \mathrm{L}$ of the cell suspension was added to each well in a 96-well polystyrene plate and incubated for $48 \mathrm{~h}$ at $37^{\circ} \mathrm{C}, 5 \% \mathrm{CO}_{2}$ in the absence and presence of $2.5 \mu \mathrm{g} / \mathrm{mL}$ of Con A (Himedia). After two days the cultures were pulsed with $0.5 \mu \mathrm{ci}$ of $\left[{ }^{3} \mathrm{H}\right]$ thymidine (specific activity 240 Bq/mmole; BRIT; Mumbai, India). Twenty-four hours later, the cells were harvested onto a glass fiber filter. Radioactivity was then measured using a liquid scintillation counter (Packard Tri-Carb Liquid Scintillation Counter) after the filters had been kept overnight at room temperature. Each test was performed in triplicates. Splenic lymphocyte proliferative response was expressed in terms of CPM of Con A stimulated (T)/CPM of unstimulated cells (C).

2.1.4. Splenic Lymphocyte Subpopulation Measurement. The splenic lymphocyte subpopulation was measured by immunofluorescent antibody staining procedure using flow cytometry [21] (Partec PAS). Briefly, an aliquot (1-2 millions) of freshly isolated cells was washed with FACS buffer (PBS with 5\% FBS and $0.1 \%$ sodium azide) and was stained with the following antibodies: fluorescein isothiocyanate(FITC-) conjugated anti-rat CD4 (clone OX-35); phycoerythrin (PE) anti-rat CD3 (clone G4.18); phycoerythrin (PE) anti-rat CD8a (clone OX-8); purified anti-rat CD45RA; IgM and fluorescein-isothiocyanate (FITC-) conjugated rat antimouse IgG1 antibody. All antibodies were procured from BD Biosciences. Cells were incubated with antibody for $30 \mathrm{~min}$ at $4^{\circ} \mathrm{C}$ and then washed three times with FACS buffer. Cells were analyzed with a flow cytometer. The samples were gated using forward versus 90-degree light scatter to exclude granulocytes and monocytes from the splenocytes population. For each test sample, 20,000 cells were analyzed.

2.1.5. Estimation of Serum Immunoglobulins. Total IgG and IgM levels were measured in serum using commercially available ELISA kit from Bethyl laboratories Inc. IgG sensitivity was $>7.8 \mathrm{ng} / \mathrm{mL}$ whereas that of IgM was $>31.25 \mathrm{ng} / \mathrm{mL}$.

2.1.6. Studies on Immune Response upon Hepatitis B Vaccination. Fourteen $(n=14) 90$-day-old obese and lean female animals of WNIN/GR-Ob strain were obtained from $\mathrm{Na}-$ tional Centre for Laboratory Animal Sciences (NCLAS). Six $(n=6)$ out of these fourteen were grouped as controls or unvaccinated animals and were given Phosphate Buffered Saline (PBS), whereas the remaining eight animals $(n=8)$ were grouped as vaccinated and were administered Hepatitis B vaccine. $4 \mu \mathrm{g}$ of Hepatitis B vaccine (Shanvac from Shantha Biotech, Hyderabad, India) was administered intramuscularly and a booster dose was injected one month after the first dose [22]. One week after the booster dose, blood was collected from the retroorbital sinus vein and the animals were sacrificed to perform the following immune parameters.

2.1.7. Antigen Specific Antibody Production. Presence of antibodies to HBsAg (a kind gift from Shantha Biotech) in the serum was determined by ELISA in flat bottom 96well plates (NUNC-Immuno Plate (polySorp)) [23]. Sera of unvaccinated lean and obese animals were taken as negative controls. Briefly, the plates were coated with $1 \mu \mathrm{g} / \mathrm{mL}$ ( $100 \mu \mathrm{L} /$ well $)$ HBsAg in bicarbonate buffer $(0.1 \mathrm{M}$, pH 9.6) and incubated overnight at $4^{\circ} \mathrm{C}$. Plates were washed with a $0.1 \%$ solution of Tween-20 in PBS between all steps in a Labsystems Microplate Washer (Finland). After coating and washing, the plates were incubated with blocking buffer (PBS with $0.1 \%$ Tween- 20 and $2 \%$ milk powder) for $1 \mathrm{~h}$ at $37^{\circ} \mathrm{C}$. Subsequently, plates were washed and serum at a dilution of $1: 5000$ was added to the wells. After $1 \mathrm{~h}$ incubation at room temperature (RT), the plates were washed and anti-rat IgG peroxidase conjugate (100 $\mu \mathrm{L}$ of $1: 5000$ dilution) (SigmaAldrich) was added and incubated for $1 \mathrm{~h}$. Plates were washed again and O-Phenylene diamine dihydrochloride (OPD) $0.3 \mathrm{mg} / \mathrm{mL}$ (Sigma-Aldrich) plus $0.006 \% \mathrm{H}_{2} \mathrm{O}_{2}$ in $0.15 \mathrm{M}$ citrate buffer, $\mathrm{pH}$ 5.0, was added. The reaction was stopped using $\mathrm{H}_{2} \mathrm{SO}_{4}$ and the plates were read for absorbance at $492 \mathrm{~nm}$ in Labsystems ELISA microplate reader.

2.1.8. Isolation and Culture of Peritoneal Macrophages. Peritoneal macrophages were obtained by washing the peritoneal 
TABLE 1: Spleen weight, lymphocyte subsets, lymphocyte proliferative response, and serum IgG and IgM levels in 3-month-old WNIN/GROb lean and obese rats.

\begin{tabular}{|c|c|c|}
\hline \multirow{2}{*}{ Immune parameters } & \multicolumn{2}{|c|}{3 month old WNIN/GR-Ob females } \\
\hline & Lean & Obese \\
\hline Spleen weight $(\mathrm{mg}) / \mathrm{g}$ body weight & $2 \pm 0.07^{*}$ & $1.3 \pm 0.05$ \\
\hline Total T cells (\%) & $43.9 \pm 1.64^{*}$ & $37.0 \pm 1.92$ \\
\hline T helper cells $(\%)$ & $38.1 \pm 1.58^{*}$ & $29.1 \pm 1.8$ \\
\hline T cytotoxic cells (\%) & $14.7 \pm 0.9$ & $16.8 \pm 0.48$ \\
\hline Total B cells (\%) & $29.5 \pm 3.22$ & $23.4 \pm 1.01$ \\
\hline Splenic lymphocyte proliferative response (T/C) & $11.6 \pm 1.95$ & $7.9 \pm 1.85$ \\
\hline IgG levels $(\mathrm{mg} / \mathrm{mL})$ & $2.02 \pm 0.184^{*}$ & $3.01 \pm 0.38$ \\
\hline IgM levels $(\mu \mathrm{g} / \mathrm{mL})$ & $16.7 \pm 1.24^{*}$ & $27.7 \pm 2.46$ \\
\hline
\end{tabular}

Values are in mean $\pm \mathrm{SE}$; ${ }^{*}<0.05$ (significant difference between lean and obese rats).

cavity with $15 \mathrm{~mL}$ of RPMI 1640 medium [24]. Washedout medium was centrifuged at $1200 \mathrm{~g}$ for $10 \mathrm{~min}$ at $4^{\circ} \mathrm{C}$. The pellet containing macrophages was suspended in RPMI 1640 medium enriched with fetal bovine serum (5\%) and gentamycin. Cell viability was determined by the trypan blue exclusion test and was $>95 \%$. Macrophage-rich cultures were obtained after $2 \mathrm{~h}$ incubation $\left(37^{\circ} \mathrm{C}, 5 \% \mathrm{CO}_{2}\right)$ of $1 \times 10^{6}$ cells $/ \mathrm{mL}$ in 24 -well polystyrene culture plates. Removal of nonadherent cells was done by washing the plate twice with RPMI 1640. The resulting adherent population consisted of $>95 \%$ peritoneal macrophages. The peritoneal macrophage cultures with and without Lipopolysaccharide (LPS- $1 \mu \mathrm{g} / \mathrm{mL}$ ) were incubated for $48 \mathrm{~h}$. The culture supernatants was then taken for the estimation of NO and TNF $\alpha$ release.

2.1.9. Nitric Oxide and TNF $\alpha$ Production by Peritoneal Macrophages. Nitrite $\left(\mathrm{NO}_{2}{ }^{-}\right)$which is the stable end product of $\mathrm{NO}$ was measured by a colorimetric assay using griess reagent. Nitrite concentration was calculated from $\mathrm{NaNO}_{2}$ standard curve [25]. The culture supernatant was collected and stored at $-80^{\circ} \mathrm{C}$ until further analysis of TNF $\alpha$ by ELISA (R\&D systems).

2.1.10. Splenic Lymphocyte Proliferation Assay to HBsAg. Splenic lymphocyte proliferation assay in the presence of hepatitis B surface antigen at a final concentration of $2.5 \mu \mathrm{g} / \mathrm{mL}$ was performed as described previously [22].

2.1.11. Determination of Cytokines from Splenocyte Culture Supernatant. $1 \times 10^{6}$ splenocytes per $\mathrm{mL}$ were added to each well in a 24-well polystyrene plate and incubated for $24 \mathrm{~h}$ at $37^{\circ} \mathrm{C}, 5 \% \mathrm{CO}_{2}$ in the absence or presence of $2.5 \mu \mathrm{g} / \mathrm{mL}$ of Concanavalin A. After $24 \mathrm{~h}$ the culture supernatants were collected and stored at $-80^{\circ} \mathrm{C}$ until further analysis of IL 2 and IL 4 by ELISA (R\&D systems) [26].

2.1.12. Statistics. Statistical analysis was conducted using SPSS 11.0 software. All data were reported as mean \pm SE. The difference in the basal immune response between obese and lean phenotypes was analyzed by Student's $t$-test. Immune response to Hepatitis B vaccination between vaccinated and

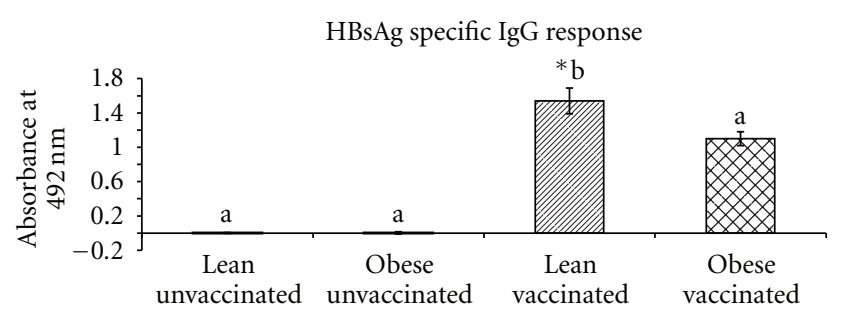

FIgURE 1: HBsAg-specific IgG response to Hepatitis B vaccine in 90-day-old WNIN/GROb lean and obese rats. Values are in Mean $\pm \mathrm{SE} ;{ }^{*} P<0.05$ (significant difference between unvaccinated and vaccinated groups of lean and obese rats).

unvaccinated animals of both phenotypes was analyzed by one way analysis of variance (ANOVA). The significant differences between groups were identified by least significant difference at $P<0.05$.

\section{Results}

3.1. Basal Immune Response. The body weight of obese animals $(400 \pm 3.9 \mathrm{~g})$ was significantly higher $(209 \pm 5.3 \mathrm{~g})$ whereas the spleen weight/g body weight was significantly lower compared to lean females. The obese animals showed significant decrease in $\mathrm{CD}^{+}$helper $\mathrm{T}$ cells, and $\mathrm{CD}^{+} \mathrm{T}$ cells compared to lean animals, whereas the $\mathrm{CD}^{+}$cytotoxic $\mathrm{T}$ cells, B cells and splenic lymphocyte proliferative response to mitogen were comparable between obese and lean animals. However, the serum IgG and IgM levels were higher in obese females compared to lean animals (Table 1).

\subsection{Immune Response upon Vaccination}

3.2.1. HBsAg Specific IgG Response. Both the obese and lean animals responded to vaccine by the production of $\mathrm{HBsAg}$ specific IgG antibody response one week after the booster dose. However the antibody response was significantly low in obese vaccinated as compared to lean vaccinated (Figure 1).

3.2.2. Nitric Oxide (NO) and Tumor Necrosis Factor Alpha (TNF $\alpha$ ) Production by Peritoneal Macrophages. Nitrate production by macrophages when stimulated with LPS was significantly higher in obese unvaccinated animals compared to 
TABLE 2: Mitogen stimulated IL2 cytokine production by splenocytes and LPS-stimulated TNF- $\alpha$ and NO production by peritoneal macrophages to Hepatitis B vaccine in 3-month-old WNIN/GR-Ob lean and obese rats.

\begin{tabular}{|c|c|c|c|c|}
\hline Immune parameters & $\begin{array}{l}\text { WNIN/GR-Ob lean } \\
\text { unvaccinated }(n=6)\end{array}$ & $\begin{array}{l}\text { WNIN/GR-Ob obese } \\
\text { unvaccinated }(n=6)\end{array}$ & $\begin{array}{l}\text { WNIN/GR-Ob lean } \\
\text { vaccinated }(n=8)\end{array}$ & $\begin{array}{l}\text { WNIN/GR-Ob obese } \\
\text { vaccinated }(n=8)\end{array}$ \\
\hline $\begin{array}{l}\text { Con A stimulated IL2 production } \\
(\mathrm{ng} / \mathrm{mL})\end{array}$ & $1505 \pm 446$ & $1087 \pm 149$ & $1423 \pm 323$ & $940 \pm 290$ \\
\hline $\begin{array}{l}\text { LPS stimulated TNF- } \alpha \text { release } \\
(\mathrm{ng} / \mathrm{mL})\end{array}$ & $1642 \pm 748^{\mathrm{a}, \mathrm{b}}$ & $430 \pm 17^{\mathrm{a}, \mathrm{b}}$ & $1974 \pm 449^{* a}$ & $384 \pm 28^{\mathrm{b}}$ \\
\hline $\begin{array}{l}\text { LPS stimulated NO production } \\
(\mathrm{ng} / \mathrm{mL})\end{array}$ & $1.96 \pm 0.35^{* a}$ & $4.4 \pm 0.35^{\mathrm{b}}$ & $4.7 \pm 0.66^{\mathrm{b}}$ & $4.25 \pm 1.34^{\mathrm{a}, \mathrm{b}}$ \\
\hline
\end{tabular}

Values are in mean $\pm \mathrm{SE} ;{ }^{*} P<0.05$ (significant difference between unvaccinated and vaccinated groups of lean and obese rats). The means bearing similar superscripts in each row do not differ significantly.

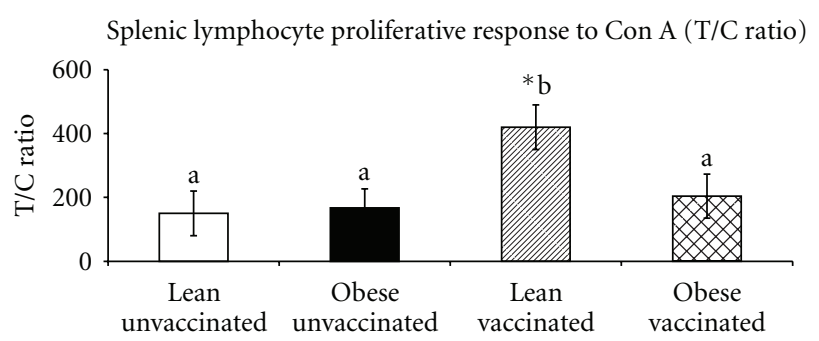

(a)

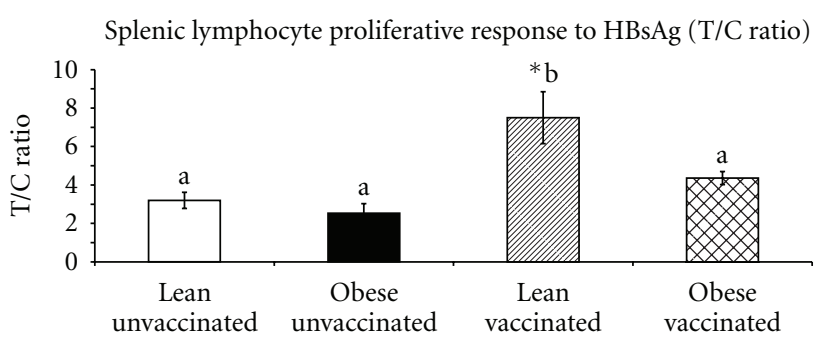

(b)

Figure 2: Splenic lymphocyte proliferative response (T/C ratio) to Con A (a) and HBsAg (b) by incorporation of $3 \mathrm{H}$ thymidine in 90 -daysold WNIN/GR-Ob lean and obese vaccinated animals. Values are Mean \pm SE; ${ }^{*} P<0.05$ (significant difference between unvaccinated and vaccinated groups of lean and obese rats).

lean unvaccinated. However, there was increased nitrate production in lean vaccinated but not in obese vaccinated. LPS stimulated TNF $\alpha$ production by peritoneal macrophages was significantly low in obese vaccinated compared to lean vaccinated (Table 2 ).

3.2.3. Splenic Lymphocyte Proliferation. In obese and lean unvaccinated animals the splenic lymphocyte proliferative response to mitogen was comparable. However, vaccination induced a significant increase in the splenic lymphocyte proliferative response to Con A and HBsAg in lean vaccinated compared to obese vaccinated animals (Figures 2(a) and 2(b)).

3.2.4. Cytokine Production by Splenocytes. IL4 was not detectable in both stimulated and unstimulated splenocytes culture supernatant, whereas IL2 was detectable in splenocytes culture supernatant only. Con A stimulated IL2 production was comparable between obese and lean unvaccinated and vaccinated animals (Table 2 ).

\section{Discussion}

Globally the incidence of IGT has been increasing in obese children and adults in both the developed and developing countries $[27,28]$. IGT is a prediabetic state and is associated with increased risk of cardiovascular diseases [29]. Rodent models have provided useful insights into the pathophysiology of obesity and obesity-related complications such as type 2 diabetes. However, such models are of substantial value in studying the complications of diabetes and the effect of prolonged hyperglycemia, but they may be less suitable for studying the milder changes that occur in the preclinical stages of type 2 diabetes, that is, prediabetes and the factors involved in the progression to overt fasting hyperglycemia and loss of glucose tolerance. Thus, WNIN/GR-Ob obese rat model with impaired glucose tolerance can be used as a suitable model to study the milder changes that are involved in the preclinical stages of type 2 diabetes in obese condition.

Obese rats showed significantly low spleen weights, $\mathrm{CD} 4^{+}$ helper $\mathrm{T}$ cells and $\mathrm{CD}^{+} \mathrm{T}$ cells which is in agreement with the findings observed in fa/fa Zucker rats [30, 31]. The splenic lymphocyte mitogenic response was comparable between obese and lean animals which is in agreement with mice-fed high fat diet, but in contrast to fa/fa Zucker rats, [32]. However, the splenic lymphocyte proliferative response to mitogen and HBsAg upon HBV was reduced in obese animals compared to lean animals. Such discrepancies in response under normal and sensitized conditions were also observed in $\mathrm{db} / \mathrm{db}$, ob/ob mice models where no difference was seen in the proliferative activity in vitro but on sensitization the obese animals exhibited decreased proliferative suggesting a deleterious microenvironment in terms of altered hormonal and metabolic status $[33,34]$.

Decreased HBsAg-specific IgG antibody response was however, seen similar to obese human subjects, where there were decreased antibody titers to Hepatitis B vaccine and tetanus toxoid [11-13]. This could be attributed to mechanical factors like insufficient dose relative to body size or suboptimal absorption and distribution of the injected vaccine under obesity [35]. 
NO generated by macrophages or the antigen-presenting cells (APCs) during the process of antigen presentation to $\mathrm{T}$ cells contributes to the control of replication or killing of intracellular microbial pathogens [36]. WNIN/GR-Ob obese unvaccinated rats showed elevated NO production by peritoneal macrophages upon stimulation with LPS compared with their lean unvaccinated animals. These observations are in agreement with the findings observed in $\mathrm{db} / \mathrm{db}$ mice wherein the heightened NO production was attributed to the hyperglycemia observed in those animals [37]. Though the basal NO levels were high, vaccination did not lead to further increase in NO production in obese, which was however shown by lean littermates. The blunted NO production by macrophages observed in WNIN/GR-Ob obese vaccinated animals may be due to the presence of high basal NO levels in macrophages of unvaccinated obese rats. Elevated NO in macrophage was shown to downregulate protein synthesis, phagocytic activity, respiratory burst, expression of MHC class II, and suppression of transcriptional activation of several genes including nitric oxide synthase 2 and may even trigger their own apoptosis [38]. However, the peritoneal macrophage NO production by euglycemic WNIN/Ob obese unvaccinated and vaccinated animals was unaltered [14].

Tumor Necrosis Factor- $\alpha$ (TNF- $\alpha$ ) secreted by monocytes or macrophages upon Lipopolysaccharide (LPS) stimulation is essential for host defense against bacterial and other pathogens [39]. Furthermore, it enhances the antigen presenting capacity and the T-lymphocyte proliferation [40]. There was no significant difference in the LPS stimulated TNF- $\alpha$ release by peritoneal macrophages between obese and lean unvaccinated animals which is in agreement with the findings in diet-induced obese rats [41]. Unlike WNIN/Ob, the LPS stimulated TNF $\alpha$ release by peritoneal macrophages was decreased in WNIN/GROb obese vaccinated animals compared to lean vaccinated animals [14].

Earlier studies had shown that the hormonal and metabolic abnormalities associated with obesity such as hyperinsulinemia and hyperlipidemia decreases cellular immune functions such as natural killer cell activity and proliferation of peripheral blood lymphocytes [42-45]. Apart from the these factors, it is also shown that in prediabetic state per se, the lymphomononuclear (LMN) cells change their energy pathway leading to anaerobic glycolysis and this abnormal energy production might cause dysfunction in LMN cells and the immune system in diabetic and prediabetic patients [46]. Furthermore, an association of Hepatitis C virus with insulin resistance among adults was observed and abnormal glucose tolerance was found to be more common in $\mathrm{HCV}$ seropositive individuals than seronegative individuals among obese participants suggesting that it could be an additional risk factor in the impairment of immune function of WNIN/GR-Ob obese rats [47].

\section{Conclusion}

WNIN/GR-Ob obese rat with IGT, a suitable model to study obesity associated prediabetic condition showed impaired or altered adaptive and innate immunity upon HBV. This inability of obese animals to respond to HBV has implications for maintenance of protective immunity and immunological memory following vaccination.

\section{Authors' Contribution}

P. Bandaru was involved in the animal handling, tissue dissection, flow cytometry, cell culture work, antibody estimation, data analysis, interpretation of data and prepared the first draft. H. Rajkumar and G. Nappanveettil drafted the manuscript, had overall supervision and gave final approval of the manuscript to be published.

\section{Acknowledgments}

The authors thank the Indian Council for Medical Research for supporting the project and M/s Shantha Biotech for providing Hepatitis B surface antigen. They thank the National Centre for Laboratory Animal Sciences (NCLAS) for taking care and maintenance of animals used in the study. They thank Mr. B. Narayana Goud and Mr. Ch. Hanumanth Reddy for their technical support.

\section{References}

[1] K. M. Flegal, B. I. Graubard, D. F. Williamson, and M. H. Gail, "Cause-specific excess deaths associated with underweight, overweight, and obesity," Journal of the American Medical Association, vol. 298, no. 17, pp. 2028-2037, 2007.

[2] M. E. Falagas and M. Kompoti, "Obesity and infection," Lancet Infectious Diseases, vol. 6, no. 7, pp. 438-446, 2006.

[3] B. J. Plotkin, D. Paulson, A. Chelich et al., "Immune responsiveness in a rat model for type II diabetes (Zucker rat, fa/fa): susceptibility to Candida albicans infection and leucocyte function," Journal of Medical Microbiology, vol. 44, no. 4, pp. 277-283, 1996.

[4] S. Ikejima, S. Sasaki, H. Sashinami et al., "Impairment of host resistance to Listeria monocytogenes infection in liver of $d b / d b$ and ob/ob mice," Diabetes, vol. 54, no. 1, pp. 182-189, 2005.

[5] S. Amar, Q. Zhou, Y. Shaik-Dasthagirisaheb, and S. Leeman, "Diet-induced obesity in mice causes changes in immune responses and bone loss manifested by bacterial challenge," Proceedings of the National Academy of Sciences of the United States of America, vol. 104, no. 51, pp. 20466-20471, 2007.

[6] A. G. Smith, P. A. Sheridan, J. B. Harp, and M. A. Beck, "Dietinduced obese mice have increased mortality and altered immune responses when infected with influenza virus," Journal of Nutrition, vol. 137, no. 5, pp. 1236-1243, 2007.

[7] J. Palmblad, D. Hallberg, and L. Engstedt, "Polymorphonuclear (PMN) function after small intestinal shunt operation for morbid obesity," British Journal of Haematology, vol. 44, no. 1, pp. 101-108, 1980.

[8] S. Tanaka, F. Isoda, Y. Ishihara, M. Kimura, and T. Yamakawa, "T lymphopaenia in relation to body mass index and TNFalpha in human obesity: adequate weight reduction can be corrective," Clinical Endocrinology, vol. 54, no. 3, pp. 347-354, 2001.

[9] A. Martí, A. Marcos, and J. A. Martínez, "Obesity and immune function relationships," Obesity Reviews, vol. 2, no. 2, pp. 131140, 2001. 
[10] O. Lamas, J. A. Martinez, and A. Marti, "T-helper lymphopenia and decreased mitogenic response in cafeteria dietinduced obese rats," Nutrition Research, vol. 22, no. 4, pp. 497506, 2002.

[11] D. J. Weber, W. A. Rutala, and G. P. Samsa, "Obesity as a predictor of poor antibody response to hepatitis B plasma vaccine," The Journal of the American Medical Association, vol. 254, no. 22, pp. 3187-3189, 1985.

[12] J. Simo Minana, M. Gaztambide Ganuza, P. Fernandez Millan, and M. Pena Fernandez, "Hepatitis B vaccine immunoresponsiveness in adolescents: a revaccination proposal after primary vaccination," Vaccine, vol. 14, no. 2, pp. 103-106, 1996.

[13] A. Eliakim, C. Schwindt, F. Zaldivar, P. Casali, and D. M. Cooper, "Reduced tetanus antibody titers in overweight children," Autoimmunity, vol. 39, no. 2, pp. 137-141, 2006.

[14] P. Bandaru, H. Rajkumar, and G. Nappanveettil, "Altered or impaired immune response upon vaccination in WNIN/Ob rats," Vaccine, vol. 29, no. 16, pp. 3038-3042, 2011.

[15] N. V. Giridharan, N. Harishankar, and M. Satyavani, "A new rat model for the study of obesity," Scandinavian Journal of Laboratory Animal Science, vol. 23, no. 3, pp. 131-137, 1996.

[16] S. M. Jeyakumar, P. Lopamudra, S. Padmini, N. Balakrishna, N. V. Giridharan, and A. Vajreswari, "Fatty acid desaturation index correlates with body mass and adiposity indices of obesity in Wistar NIN obese mutant rat strains WNIN/Ob and WNIN/GR-Ob," Nutrition and Metabolism, vol. 6, article no. 27, 2009.

[17] A. Sheril, S. M. Jeyakumar, T. Jayashree, N. V. Giridharan, and A. Vajreswari, "Impact of feeding polyunsaturated fatty acids on cholesterol metabolism of dyslipidemic obese rats of WNIN/GR-Ob strain," Atherosclerosis, vol. 204, no. 1, pp. 136140, 2009.

[18] K. S. Jayaraman, "'Sumo' rats set researchers on hunt for obesity genes," Nature Medicine, vol. 11, no. 2, p. 108, 2005.

[19] N. Harishankar, A. Vajreswari, and N. V. Giridharan, "WNIN/ GR-Ob-an insulin-resistant obese rat model from inbred WNIN strain for studies on obesity associated with diabetes," Indian Journal of Medical Research. In press.

[20] S. Moriguchi, M. Kalo, K. Sakai, S. Yamamoto, and E. Shimizu, "Decreased mitogen response of splenic lymphocytes in obese Zucker rats is associated with the decreased expression of glucose transporter 1 (GLUT- 1)," American Journal of Clinical Nutrition, vol. 67, no. 6, pp. 1124-1129, 1998.

[21] M. A. Pahlavani, D. A. Vargas, T. R. Evans, J. H. Shu, and J. F. Nelson, "Melatonin fails to modulate immune parameters influenced by calorie restriction in aging Fischer 344 rats," Experimental Biology and Medicine, vol. 227, no. 3, pp. 201207, 2002.

[22] F. Ozgenc, G. Aksu, F. Kirkpinar et al., "The influence of marginal zinc deficient diet on post-vaccination immune response against hepatitis B in rats," Hepatology Research, vol. 35, no. 1, pp. 26-30, 2006.

[23] A. Sleijffers, J. Garssen, F. R. de Gruijl et al., "UVB exposure impairs immune responses after hepatitis B vaccination in two different mouse strains," Photochemistry and Photobiology, vol. 75, no. 5, pp. 541-546, 2002.

[24] M. C. Blanc, C. Moinard, A. Béziel, S. Darquy, L. Cynober, and J. P. De Bandt, "Arginine and glutamine availability and macrophage functions in the obese insulin-resistant Zucker rat," Journal of Cellular Physiology, vol. 202, no. 1, pp. 153-159, 2005.

[25] K. D. Kroncke, K. Fehsel, and V. Kolb-Bachofen, "Inducible nitric oxide synthase and its product nitric oxide, a small molecule with complex biological activities," Biological Chemistry Hoppe-Seyler, vol. 376, no. 6, pp. 327-343, 1995.

[26] N. Mito, T. Hosoda, C. Kato, and K. Sato, "Change of cytokine balance in diet-induced obese mice," Metabolism, vol. 49, no. 10, pp. 1295-1300, 2000.

[27] T. E. Saaristo, N. C. Barengo, E. Korpi-Hyövälti et al., "High prevalence of obesity, central obesity and abnormal glucose tolerance in the middle-aged Finnish population," BMC Public Health, vol. 8, article 423, 2008.

[28] K. Supreet and K. Umesh, "Impaired glucose tolerance and diabetes mellitus in obese children," Indian Pediatrics, vol. 47, no. 4, pp. 362-363, 2010.

[29] E. L. Barr, P. Z. Zimmet, T. A. Welborn et al., "Risk of cardiovascular and all-cause mortality in individuals with diabetes mellitus, impaired fasting glucose, and impaired glucose tolerance: The Australian Diabetes, Obesity, and Lifestyle Study (AusDiab)," Circulation, vol. 116, no. 2, pp. 151-157, 2007.

[30] M. R. Ruth, C. G. Taylor, P. Zahradka, and C. J. Field, "Abnormal immune responses in fa/fa Zucker rats and effects of feeding conjugated linoleic acid," Obesity, vol. 16, no. 8, pp. 17701779, 2008.

[31] S. Tanaka, F. Isoda, T. Yamakawa, M. Ishihara, and H. Sekihara, "T lymphopenia in genetically obese rats," Clinical Immunology and Immunopathology, vol. 86, no. 2, pp. 219-225, 1998.

[32] C. Verwaerde, A. Delanoye, L. Macia, A. Tailleux, and I. Wolowczuk, "Influence of high-fat feeding on both naive and antigen-experienced T-cell immune response in DO10.11 mice," Scandinavian Journal of Immunology, vol. 64, no. 5, pp. 457-466, 2006.

[33] R. K. Chandra, "Cell-mediated immunity in genetically obese (C57BL/6J ob/ob) mice," American Journal of Clinical Nutrition, vol. 33, no. 1, pp. 13-16, 1980.

[34] G. Fernandes, B. S. Handwerger, E. J. Yunis, and D. M. Brown, "Immune response in the mutant diabetic C57BL/Ks-db+ mouse," Journal of Clinical Investigation, vol. 61, no. 2, pp. 243-250, 1978.

[35] F. B. Hollinger, "Factors influencing the immune response to hepatitis B vaccine, booster dose guidelines, and vaccine protocol recommendations," The American Journal of Medicine, vol. 87, no. 3, pp. 36S-40S, 1989.

[36] C. Bogdan, M. Röllinghoff, and A. Diefenbach, "The role of nitric oxide in innate immunity," Immunological Reviews, vol. 173, pp. 17-26, 2000.

[37] S. N. Zykova, T. G. Jenssen, M. Berdal, R. Olsen, R. Myklebust, and R. Seljelid, "Altered cytokine and nitric oxide secretion in vitro by macrophages from diabetic type II-like $d b / d b$ mice," Diabetes, vol. 49, no. 9, pp. 1451-1458, 2000.

[38] M. John, X. Qiao-wen, and N. Carl, "Nitric oxide and macrophage function," Annual Review of Immunology, vol. 15, pp. 323-350, 1997.

[39] M. Zembala, D. Kowalczyk, J. Pryjma et al., "The role of tumor necrosis factor in the regulation of antigen presentation by human monocytes," International Immunology, vol. 2, no. 4, pp. 337-342, 1990.

[40] S. Yokota, T. D. Geppert, and P. E. Lipsky, "Enhancement of antigen- and mitogen-induced human T lymphocyte proliferation by tumor necrosis factor-alpha," Journal of Immunology, vol. 140, no. 2, pp. 531-536, 1988.

[41] S. Bedoui, E. Velkoska, S. Bozinovski, J. E. Jones, G. P. Anderson, and M. J. Morris, "Unaltered TNF- $\alpha$ production by macrophages and monocytes in diet-induced obesity in the rat," Journal of Inflammation, vol. 2, p. 2, 2005.

[42] K. N. Traill and G. Wick, "Lipids and lymphocyte function," Immunology Today, vol. 5, no. 3, pp. 70-76, 1984. 
[43] M. I. Gurr, "The role of lipids in the regulation of the immune system," Progress in Lipid Research, vol. 22, no. 4, pp. 257-287, 1983.

[44] M. G. Pallavicini and W. K. Nichols, "Inhibition of lymphocyte blastogenesis by factor(s) in a alloxan diabetic rat plasma," Diabetes, vol. 25, pp. 14-22, 1976.

[45] A. M. Attallah, H. Abdelghaffar, A. Fawzy et al., "Cell-mediated immunity and biological response modifiers in insulin-dependent diabetes mellitus complicated by end-stage renal disease," International Archives of Allergy and Applied Immunology, vol. 83, no. 3, pp. 278-283, 1987.

[46] L. Ozsari, N. Karadurmus, M. Sahin, G. Uckaya, A. U. Ural, and M. Kutlu, "Comparison of lymphomononuclear cell energy metabolism between healthy, impaired glucose intolerance and type 2 diabetes mellitus patients," Endocrine, vol. 37, no. 1, pp. 135-139, 2010.

[47] A. A. Howard, Y. Lo, and M. Floris-Moore, "Hepatitis C virus infection is associated with insulin resistance among older adults with or at risk of HIV infection," AIDS, vol. 21, no. 5, pp. 633-641, 2007. 


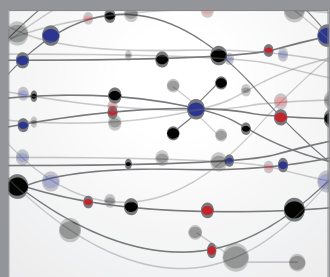

The Scientific World Journal
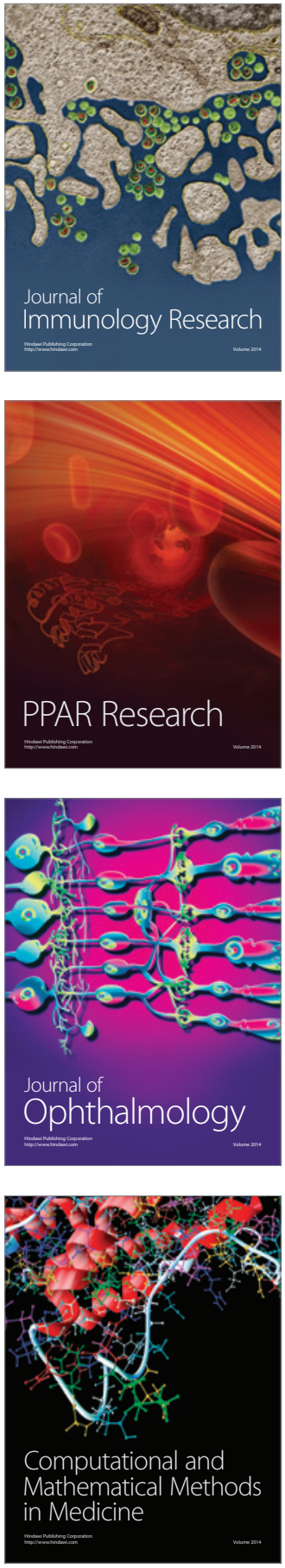

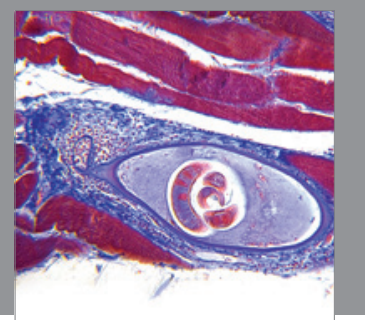

Gastroenterology

Research and Practice
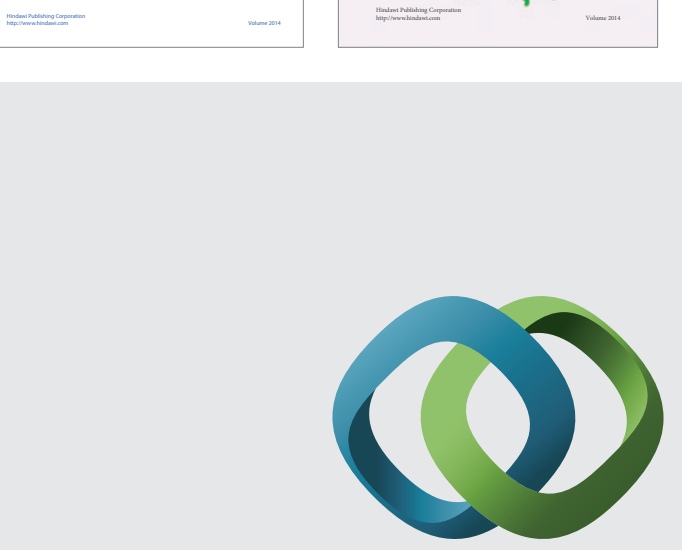

\section{Hindawi}

Submit your manuscripts at

http://www.hindawi.com
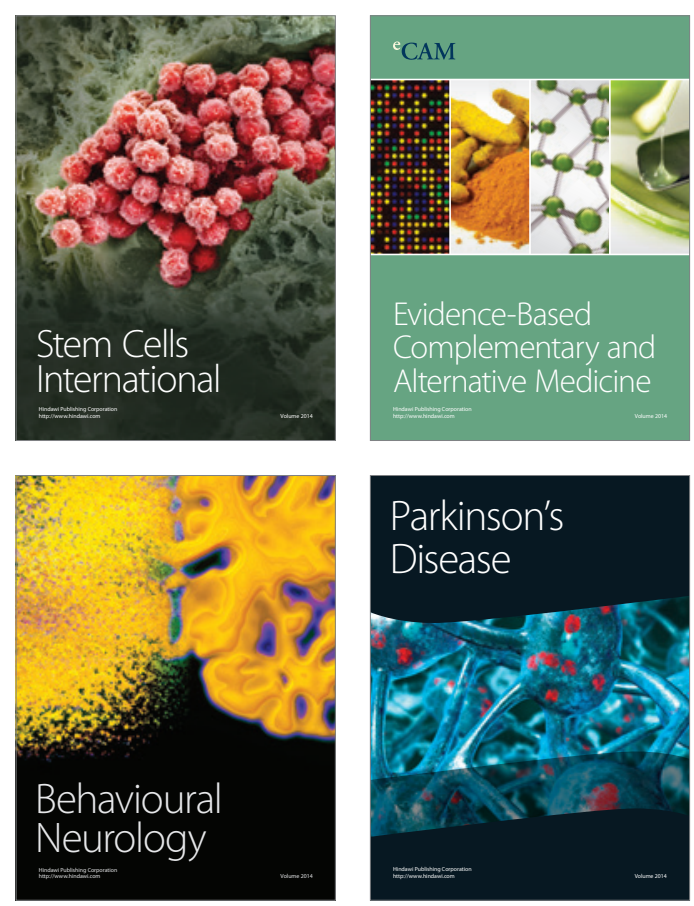

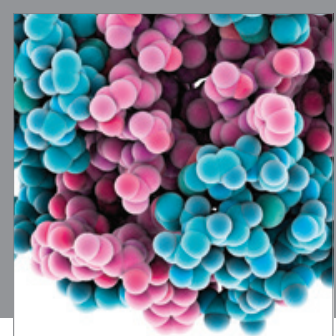

Journal of
Diabetes Research

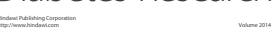

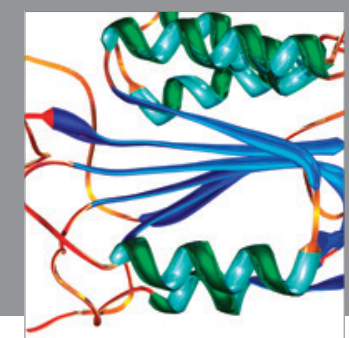

Disease Markers
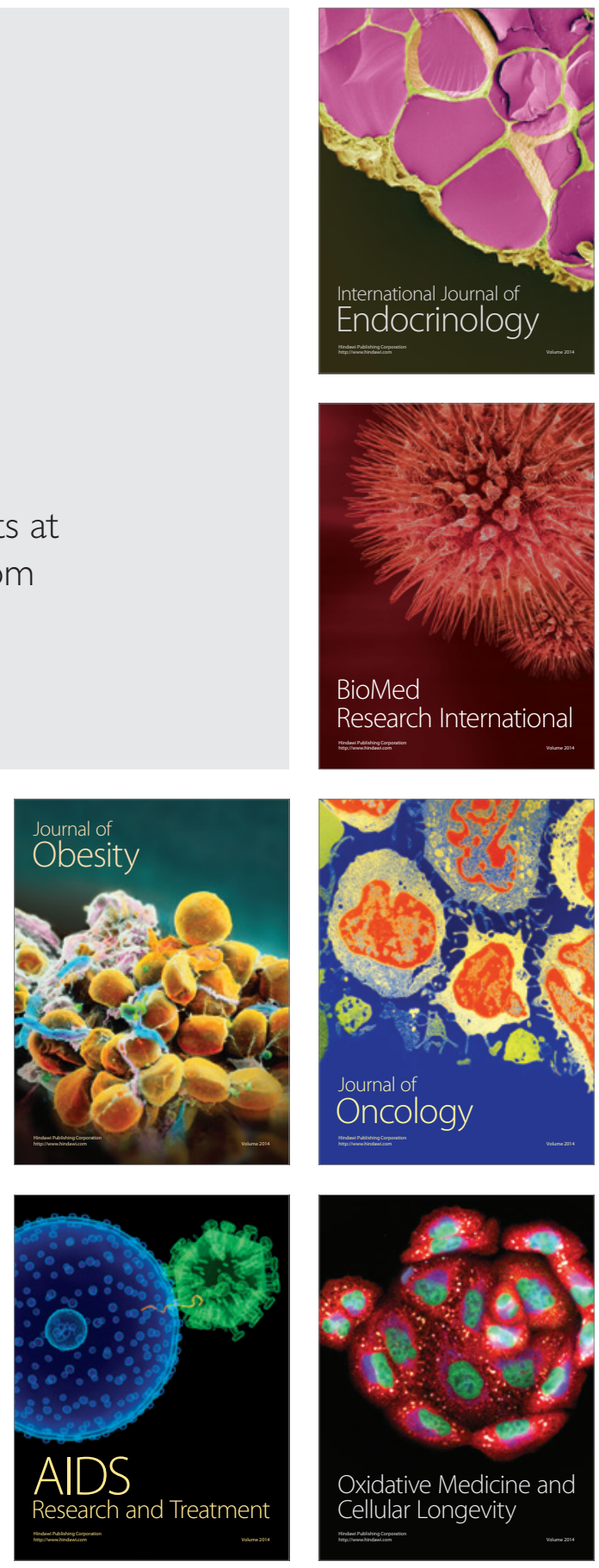